\title{
Why Observing Violence Increases the Risk of Violent Behavior by the Observer
}

\section{Rowell Huesmann and Lucyna Kirwil}

\section{Overview}

Severe violent behavior is almost always the product of predisposing individual differences and precipitating situational factors (Huesmann, 1998). One important environmental experience that contributes both to predisposing a person to behave more violently in the long run and to precipitating violent behavior in the short run is exposure to violence. Psychological theories that have emerged over the past few decades now explain the short-term precipitating effects mostly in terms of priming, simple imitation, and excitation transfer. However, the long-term predisposing effects involve more complex processes of observational learning of cognitions and of emotional desensitization.

In this chapter these theories are elaborated, and the compelling empirical evidence in support of these theories from experiments and longitudinal field studies is reviewed. We explain why the processes operate equally well from exposure to reallife violence or exposure to dramatic violence in the mass media. We focus particu- larly on the role of low emotional arousal and diminished emotional reactions to violence as consequences of exposure to violence and precursors of violent behavior. We argue that anticipated emotional responses play an important role in the cognitive processing that controls violent behavior. Abnormal violent behavior is not viewed as a consequence of "deficient" processing, but rather as a consequence of "different" processing.

\section{Introduction}

Sudden acts of individual violence have long fascinated Americans far out of proportion to the damage they cause. Whether it is "Lizzie Bordon taking an ax and giving her husband 40 whacks," Leopold and Loeb kidnapping and murdering a child for no apparent reason, Charles Manson and cronies killing Hollywood celebrities, or Dillon Klebold and Eric Harris murdering classmates in Columbine High School, the attention of the public becomes riveted on these events. We seek to understand what seems inexplicable, we seek to find the underlying 
cause that made these perpetrators do what they did, and we try to differentiate these perpetrators from the others around us who look no different on the surface.

In these environments there are many villains that are easy to blame, and usually they all receive some blame without any evidence to support the claim - poor parenting, defective genes, bad friends, easy availability of guns, and most recently media violence. Some people believe that the only reason some of these causes (e.g., gun availability and media violence) are blamed is that they are easy targets that deflect attention from the individual and from other more complex causes that society does not want to address. There may be some truth to this claim, but it does not relieve scholars of the responsibility of critically addressing each cause in a more dispassionate manner. Such scientific critical evaluation must involve two important linked components: (1) a theory that illuminates a psychological process by which the hypothesized cause produces the effect on violent behavior and (2) a body of empirical evidence that supports the theory.

In this chapter we focus on this question: to what extent does individuals' exposure to violent behavior - in their personal world or in the larger world around them through the mass media - increase the risk for them behaving violently? The debate on this topic has long been passionate in the political and public arena probably because of the perceived threats to "free expression" and profits in the marketplace posed by finding media violence unquestionably guilty. However, the scientific debate has become more muted as evidence and theory have accumulated that exposure to violent behavior undoubtedly has an effect. The psychological processes through which exposure to violence in one's personal world or in one's media world engenders an increased risk of behaving violently are now understood, and the empirical evidence showing that exposure to violence increases risk has accumulated to the point of being indisputable. We review both these processes and the empirical evidence in this chapter. However, we must start by placing this chapter in the framework of the other chapters in this book.

Despite the mass media's desire to pin violent acts on single underlying causes, violent behavior is almost never the result of a single cause. Violent behavior is usually the consequence of the convergence of multiple, longer term predisposing factors that have made an individual more receptive to violence and of multiple precipitating factors that have stimulated the individual to violence in the short run. Exposure to violence can play either role, we argue, but it is only one of many important factors as this book illustrates. Critics of the research (e.g. Freedman, 2002; Rhodes, 2000) often tear down the straw dog that media violence is the number one cause of violence in society. These are disingenuous exercises as no competent researcher considers the effects of exposure to violence (in the real world or in the mass media) to be anything more than one significant risk factor for violent behavior among many significant risk factors.

\section{How Does Exposure to Violence Increase Risk for Violence}

Although the underlying tenets of the current theories of media-violence effects were formulated decades ago (see Bandura, 1973; Bandura, Ross, \& Ross, 1961, $1963 \mathrm{a}, \mathrm{b}, \mathrm{c}$; Berkowitz, 1962 ; Eron, Walder, \& Lefkowitz, 1971), researchers from a variety of disciplines, primarily psychology, communication, and sociology, have developed, tested, and refined ever-better theoretical models accounting for the consequences of exposure to media violence. The generally accepted theories that have evolved not only explain why exposure to media violence increases aggressive and violent behavior but also suggest numerous factors that might exacerbate or mitigate the effect. These models (e.g., Anderson \& Bushman, 2001; Dodge, 1986; 1993; Huesmann, 1982a,b, 1988, 1997, 1998) generally fall under the rubric of social-cognitive information-processing models. Such models focus on how people perceive, think, 
learn, and come to behave in particular ways as a result of interactions with their social world, a world that includes observation of and participation in real social interactions (e.g., with parents and peers), as well as fictional social interactions (e.g., with various forms of media). These models explain how - within the overall structure of multiple predisposing individual-difference factors interacting with multiple precipitating situational factors to instigate violent behavior - observation of violence plays a role on both sides of the equation. It plays a role as something that predisposes individuals in the long run to be more likely to behave violently, and it plays a role as something that precipitates violent behavior in the short run.

\section{The Social-Cognitive Information-Processing Model}

Over the past three decades at least three similar information-processing models have been proposed to explain the psychological processing underlying social information processing (e.g., Anderson \& Bushman, 2001; Dodge, 1986, 1993; Huesmann, 1982 a, $1988,1997,1998)$. Although these models differ in their details, all view the social problem-solving process as one in which situational factors are evaluated, social scripts are retrieved, and these scripts are evaluated until one is selected to guide behavior. The latest revision of Huesmann's model is displayed in Figure 28.1 and is used below to describe the psychological processes through which exposure to violence exerts both short-term and long-term effects.

The model describes the information flow and decision processes that occur when an individual is faced with any social decision. The processes begin with evaluation of the social situation and end with the decision to behave in a certain way and then with the post-hoc self-evaluation of the consequences of behaving that way. The solid lines connecting the bold descriptions of processes in Figure 28.1 represent the flow of informa- tion, whereas the dotted lines represent the causal influences of one factor on another.

Four cognitive/emotional factors play important roles in individual differences in social problem solving according to this model: emotional predispositions, world schemas, social scripts, and normative beliefs. Central to the model is the concept that social behavior is controlled to a great extent by social scripts. Scripts are sets of "production rules" representing sequences of expected behaviors and responses, and they describe how to deal with a variety of situations, including conflict (Abelson, 1981; Anderson \& Huesmann, 2003; Huesmann, 1988, 1998; Huesmann \& Miller, 1994). Scripts are stored in a person's memory and are used as guides for behavior and social problem solving. A script incorporates both procedural and declarative knowledge and suggests what events are to happen in the environment, how the person should behave in response to these events, and what the likely outcome of those behaviors would be. It is presumed that while scripts are first being established they influence the child's behavior through "controlled" mental processes (Schneider \& Shriffrin, 1977; Shriffrin \& Schneider, 1977), but these processes become "automatic" as the child matures. Correspondingly, scripts that persist in a child's repertoire, as they are rehearsed, enacted, and generate consequences, become increasingly more resistant to modification and change. A more violent person is generally a person whose repertoire of social scripts emphasizes violence.

World schemas are a second kind of cognition assumed to influence behaviors. Such schemas are the database that the individual employs to evaluate environmental cues and make attributions about others' intentions. These attributions in turn will influence the search for a script for behaving. An individual who believes the world is a mean place is more likely to make hostile attributions about others' intent and consequently more likely to retrieve a more aggressive script.

Normative beliefs are a third kind of cognitive schema hypothesized to play a central role in regulating aggressive behavior. 


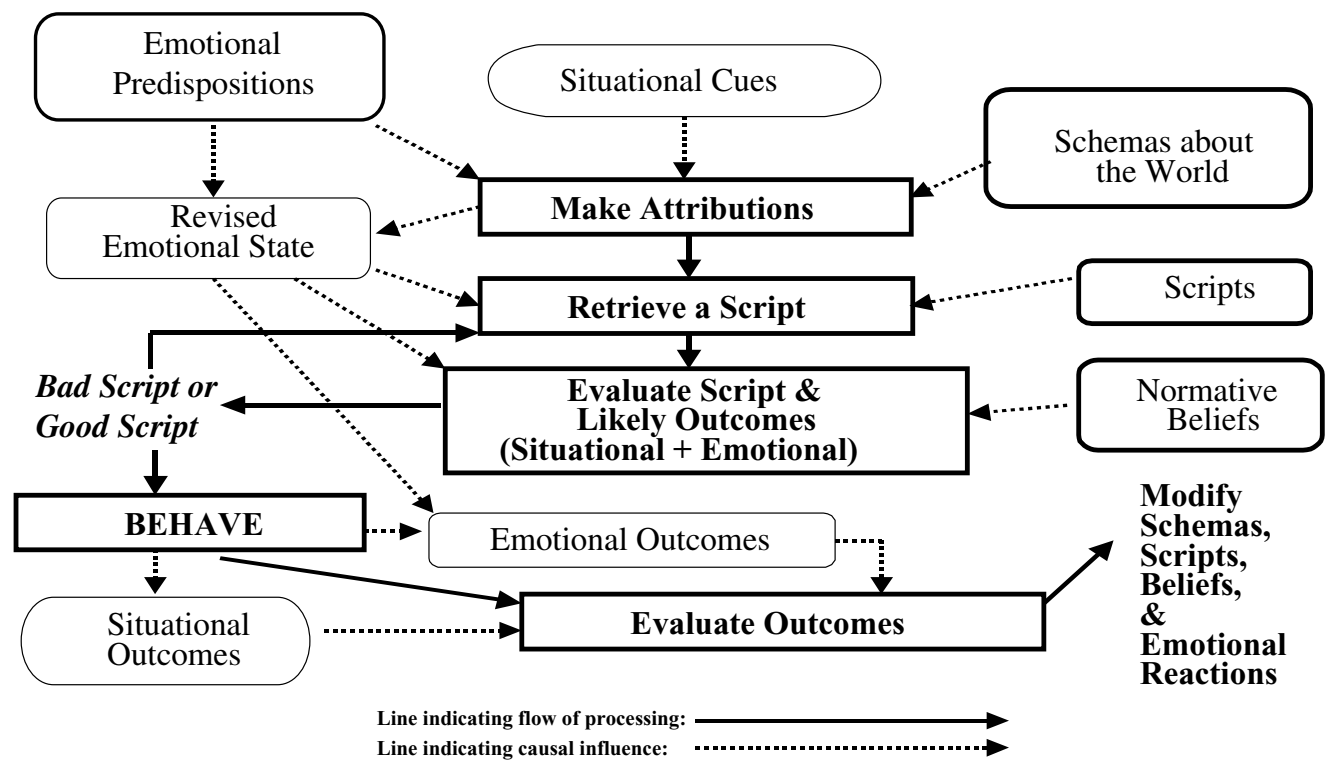

Figure 2 8.1. The information-processing social-cognitive model for social problem solving. The rounded boxes in bold represent enduring cognitive and emotional predispositions that differ across individuals. Flow of information processing is indicated by solid arrows, and causal influences are indicated by dotted arrows.

Normative beliefs are cognitions about the appropriateness of aggressive behavior. They are related to perceived social norms, but are different in that they concern what's "right for you." Normative beliefs are used to interpret other's behaviors, to guide the search for social scripts, and to filter out inappropriate scripts and behaviors. An individual who believes it is wrong for them to hita female is likely to reject retrieved scripts that involving hitting females.

Finally, individual differences in emotional predispositions involve a variety of emotion-related tendencies, including a person's overall level of arousal, a person's propensity to become angered, a person's ability to regulate and control his or her emotions, and the associations between situations and emotions that an individual holds. In a social problem-solving situation a person's initial emotional state is modified by the situation and the person's attributions about the situation. The exact relation between propensities toward violence and emotional predispositions depends on the kind of aggressive and violent behavior (e.g., proactive or reactive). Those quick to anger and poor at regulating their emotions are more likely to retrieve violent scripts and thus behave reactively violently. Those who are underaroused and do not experience intense emotions should not be particularly likely to retrieve violent scripts, but, if such a script meets the goals of the situation, they would also not be likely to reject it because of the negative emotional outcomes it might have. Whereas normal individuals may reject many scripts when they imagine the negative emotional consequences of the script during the script evaluation phase, underaroused individuals are less likely to feel any negative emotions during the evaluation phase.

In any given social setting, therefore, the characteristics of the situation interact with these four individual-difference factors to determine how the individual behaves. Imagine a teen-aged male suddenly discovering his girlfriend holding hands with another male. He makes attributions about what is happening on the basis of his current emotional state and his schemas about the world. Perhaps these lead to hostile attributions. His anger increases, and he is more likely to 
access a violent script for how to behave. If his repertoire of scripts is heavily loaded with aggressive scripts, accessing one becomes even more likely. He retrieves a script to hit his girlfriend. He evaluates the likely outcomes of the script and filters it through his normative beliefs. Does he feel any negative emotions as he imagines hitting the girl? Does he expect any negative consequences? Is hitting the girl consistent with his normative beliefs about what is OK for him to do? If all these tests are passed, he hits the girl. Finally, he may modify his schemas, scripts, normative beliefs, or emotional predispositions on the basis of the actual outcomes.

\section{Short-Term Effects of Exposure to Violence}

This model allows for three ways in which the exposure to violence can increase the risk of violent behavior in the observer in the short run: (1) the observed violent scene primes the retrieval of social scripts for violence that the observer has previously acquired; (2) the observer imitates immediately what he or she has just seen to solve another social problem; or (3) the observer becomes aroused by the violence he or she sees and that arousal increases the risk of behaving violently to solve a social problem.

\section{Priming of Violent Scripts and Schemas}

Neuroscientists and cognitive psychologists have discovered that the human mind often acts as an associative network in which ideas are partially activated (primed) by associated stimuli in the environment (Fiske \& Taylor, 1984). An encounter with some event or stimulus can prime, or activate, related concepts and ideas in a person's memory even without the person being aware of this influence (Bargh \& Pietromonaco, 1982). For example, exposure to violent scenes may activate a complex set of associations that are related to aggressive ideas or emotions, thereby temporarily increasing the accessibility of aggressive thoughts, feelings, and scripts (including aggressive action tendencies). In other words, aggressive primes or cues make aggressive schemas more easily available for use in processing other incoming information, creating a temporary interpretational filter that biases subsequent perceptions. If these aggressive schemas are primed while certain events - such as ambiguous provocation - occur, the new events are more likely to be interpreted as involving aggression, thereby increasing the likelihood of an aggressive response. Priming effects related to aggression have been empirically demonstrated both for cues usually associated with violence, such as weapons (Anderson, Benjamin, \& Bartholow, 1998; Bartholow, Anderson, Benjamin, \& Carnagey, 2005; Berkowitz \& LePage, 1967 ; Carlson, MarcusNewhall, \& Miller, 1990), and for initially neutral cues that have been observed repeatedly to be connected to violence, such as the color of a room in which violence is repeatedly observed (Leyens \& Fraczek, 1983).

Priming effects are often seen as purely short-term influences. But, of course, the aggressive script or schema being primed may have been acquired long before the exposure to violence that primes its activation. In addition, research by cognitive and social-cognitive scientists has shown that repeated priming of certain scripts or schemas eventually makes them chronically accessible. In essence, frequently primed aggression-related thoughts, emotions, and behavioral scripts become automatically and chronically accessible. That is, they become part of the normal internal state of the individual, thereby increasing the likelihood that any social encounter will be interpreted in an aggression-biased way, and therefore increasing the likelihood of aggressive encounters throughout the individual's life (e.g., Anderson \& Huesmann, 2003).

\section{Simple Imitation of Violent Scenes}

In recent years indisputable evidence has accumulated that human and primate young have an innate tendency to imitate whomever they observe (Meltzoff, 2005; Meltzoff \& Moore, 1977, 2000). They 
imitate expressions in early infancy and imitate behaviors by the time they can walk. Aggressive behaviors are no different from other observable motor behavior in this regard. Thus, the hitting, grabbing, pushing behaviors that young children see around them or in the mass media are generally immediately mimicked unless the child has been taught not to mimic them (Bandura, 1977; Bandura, Ross, \& Ross, 1961, $1963 a, b, c)$. Furthermore, there is good reason to believe that the automatic imitation of expressions on others' faces also leads to the automatic activation of the emotion that the other was experiencing, as expressions are innately linked to emotions (Prinz, 2005: Zajonc, Murphy, \& Inglehart, 1989).

This empirical evidence for automatic imitation in humans has been given added import by an explosion of neurophysiological findings (Iacoboni et al., 1999) and computational theorizing (Schaal, 1999) that explain how imitation works. The demonstration in the mid-199os of the existence of "mirror neurons" that fire either when an action is observed or when it is executed (Gallese, Fadiga, Fogassi, \& Rizzolatti, 1996; Rizzolatti, 2005) provided a strong basis for understanding the innate neurophysiological basis of imitation. Most recently this work has been connected directly with theorizing about social cognitions in adults and how they are acquired (Meltzoff \& Decety, 2003). At the same time, the expanding work in artificial intelligence on learning by example (e.g., Dautenhahn \& Nehaniv, 2002; Schaal, 1999) has stimulated some developmentalists to think more broadly about the role of imitation and observation in creating the schemas, scripts, beliefs, and emotional dispositions we call the self. The kind of imitation that is involved most often in very short-term effects of exposure to violence is a less complex kind of imitation that does not involve the need to form a lasting or abstracted cognitive representation of the observed act, but only a "mirror" representation of it. However, that does not mean that the process of imitation in general is not a complex cognitive process. As Hurley and Chatter $(2005$, p. 1) recently wrote,
Imitation is often thought of as a low level, cognitively undemanding, even childish form of behavior. But recent work across a variety of sciences argues that imitation is a rare ability, fundamentally linked to characteristically human forms of intelligence, and in particular to language, culture, and the ability to understand other minds.

and from a generalists' point of view Brass \& Heyes (2005, p. 1) add,

Imitation is based on the automatic activation of motor representations by movement observation. These externally triggered motor representations are then used to reproduce the observed behavior. This imitative capacity depends on learned perceptual-motor links. Finally, mechanisms distinguishing self from other are implicated in the inhibition of imitative behavior.

\section{Arousal and Excitation Transfer}

Observing violence is highly emotionally arousing (e.g., disturbing) for most people. That is, it increases heart rate, the skin's conductance of electricity, and other physiological indicators of arousal. There is evidence that this arousal can increase aggression in three different ways. First, the arousal that violence produces is experienced as unpleasant by most people. As such it can increase aggression inclinations just like any other unpleasant stimuli (e.g., loud noises, hot temperatures, foul odors, frustrations, provocations; Berkowitz, 1983). This would be particularly true if the arousal stimulated by the violence is "angry arousal." Second, arousal, regardless of the reason for it, can reach such a peak that performance on complex tasks declines, inhibition of inappropriate responses is diminished, and dominant scripts tend to be displayed in social problem solving. High arousal seems to energize or strengthen whatever an individual's dominant action tendency happens to be at the time. Consequently, if a person is provoked or otherwise instigated to aggress right after being aroused by a violent film, heightened aggression can result (e.g., Geen \& 
O'Neal, 1969). Third, if a person who is aroused by a violent film misattributes his or her arousal to a provocation by someone else, the propensity to behave aggressively in response to that annoyance is increased (e.g., Bryant \& Zillmann, 1979; Zillmann, Bryant, Cominsky, \& Medoff, 1981). Thus, people tend to react more violently to provocations immediately after watching exciting movies - violent, sexual, or otherwise exciting - than they do at other times. This kind of effect, called "excitation transfer," is usually short-lived, perhaps lasting only minutes.

Such arousal-transfer effects can occur with any kind of exciting activity, not just exciting movies, TV shows, music videos, or video games. For this reason, the arousal properties of violent media have not drawn as much attention as their other consequences. Nonetheless, it bears noting that frequent episodes in which exposure to violent media is followed by frustrating or provoking events could well lead to an increase in the viewers' aggressive social encounters, which in turn can affect their self-images and the aggressiveness of their social environment. Indeed, recent research shows that playing a violent video game for as little as 10 minutes increases the player's automatic association of "self" with aggressive actions and traits (Uhlmann \& Swanson, 2004).

\section{Long-Term Socializing Effects of Exposure to Violence}

In addition to the short-term precipitating effects that exposure to violence has on violent behavior, exposure to violence also has long-term socializing effects that predispose those exposed to violence to be more at risk of behaving violently for a long time. These socialization processes alter the four enduring individual differences that affect social behavior according to the model in Figure 28.1: (1) world schemas, (2) social scripts, (3) normative beliefs, and (4) emotional predispositions. Of course, any of these individual differences can be altered through the enactive learning processes (classical and operant conditioning) by which people learn on the basis of experience. However, repeated exposure to violence changes these individual differences through two other complex learning processes - (1) the observational learning of cognitions (world schemas, scripts, and normative beliefs) that make violent behavior more likely and (2) learned changes in emotional predispositions relevant to violence.

\section{Observational Learning from Exposure to Violence}

As described above, humans begin imitating other humans at a very early age, and the observation of others' behaviors is the likely source of many of a young child's motor and social skills (Bandura, 1977; Meltzoff \& Moore, 1977). The innate neurophysiological processes that make imitation automatic (probably involving mirrorneurons) allow the incorporation into the child's repertoire of simple social scripts at a very young age. Social interactions then hone these behaviors that children first acquire through observation of others, but observational learning remains a powerful mechanism for the acquisition of new social behaviors throughout childhood and maturity. As a child grows older, scripts are acquired instead of simple behaviors. Then, the acquired scripts become more abstract, and beliefs and attitudes are acquired from inferences made about observed social behaviors (Guerra, Huesmann, \& Spindler, 2003). Theoretically, children can be expected to learn from whomever they observe - parents, siblings, peers, or media characters. Much of this learning takes place without an intention to learn and without an awareness that learning has occurred.

According to observational-learning theory, the likelihood that an individual will acquire an observed social script is increased when the model performing the script is similar to or attractive to the viewer, the viewer identifies with the model, the context is realistic, and the viewed behavior is followed by rewarding consequences (Bandura, 1977). The reinforcements a person receives when imitating a behavior are largely responsible 
for whether the behavior persists. For example, youngsters might be rewarded or punished by people in their social environment (parents, teachers, peers) for the actions they exhibit, or they might vicariously experience the rewards or punishments other persons obtain when these others imitate the portrayed behavior. Through imitation and reinforcement, children develop habitual modes of behavior (e.g., Bandura, 1977, 1986; Huesmann, 1997). Whether observational learning leads to long-term effects of media violence depends in part on the consequences that the imitated behaviors bring.

It is theorized that children learn not only specific behaviors from models but also more generalized, complex social scripts. Once learned, such scripts serve as cognitive guides for future behavior. For example, from observing violent people, children may learn that aggression can be used to try to solve interpersonal conflicts. As a result of mental rehearsal (e.g., imagining this kind of behavior) and repeated exposure, this approach to conflict resolution can become well established and easily retrieved from memory. Finally, through inferences they make from repeated observations, children also develop beliefs about the world in general (e.g., is it hostile or benign) and about what kind of behavior is acceptable.

Observational learning and imitation are often thought of as conscious processes, but that need not be the case. Recent theoretical and empirical work (e.g., Bargh \& Chartrand, 1999; Neuman \& Strack, 2000) suggests that some types of imitative behaviors are very automatic, nonconscious, and likely to be short-lived. It has been demonstrated that movements of human and robotic stimuli as well as their schematic visual presentations elicited automatic imitation in observers (Press, Bird, Flach, \& Heyes, 2005). Fadiga, Craighero \& Olivier (2005, p. 217) argue that

a large body of evidence supports the view that perception of others' actions is constantly accompanied by motor facilitation of the observer's CS system. This facilitation is not only present during action obser- vation but also while listening to actionrelated sounds and, more interestingly, while listening to speech.

The motor cortex dynamically replicates the observed actions, as if they were executed by the observer.

Similarly, observational learning of complex scripts and schemas (e.g., beliefs, attitudes, and other types of knowledge that guide perception, interpretation, and understanding) can also occur outside of awareness, even with no immediate imitation of behaviors. Theoretically, it should not matter much for the long-term consequences of observation of violent behavior whether or not the child is aware of its influence. Repeated observation of aggressive behavior should increase the likelihood that children will incorporate aggressive scripts into their repertoires of social scripts, particularly if their own use of those scripts is followed by reinforcement.

One facet of observational learning from exposure to violence is sometimes called cognitive desensitization to violence. More properly, desensitization is used to refer to emotional changes that occur with repeated exposures. However, when repeated exposures to violence are followed by changes in beliefs about violence - from the belief that violence and aggression are rare and unlikely behavior to the belief that violence is common, mundane, and inevitable - the process is sometimes called cognitive desensitization. Such cognitive desensitization results in more approving violence beliefs, in more positive moral evaluations of aggressive acts, and in more justification for inappropriate behavior inconsistent with social and an individual's moral norms. As a result, the individual may develop stronger pro-violence attitudes (i.e. attitudes approving violence as a means of regulating interpersonal contacts; Huesmann, 1998) .

\section{Changes in Emotions Associated With Violence and Provocation}

In the earlier material on short-term effects, we discussed the role that heightened 
arousal from observing violence can play in increasing aggression in the short run. Increased arousal and particularly increased negative affect increase the risk for aggression. However, emotional arousal has a much more complex relation in the long run. Individual differences in the propensity to be aroused seem to interact with learning experiences to produce new individual differences in responsiveness to violence that have lasting effects on the risk for aggressive behavior. As a group these effects have come to be known in the literature as sensitization effects and desensitization effects. Sensitization refers to the process of becoming more likely to experience negative effect and arousal from scenes that are "provoking," whereas desensitization refers to the process of becoming less likely to experience negative effect and arousal from scenes that are very violent (see also our following section on 'Emotional Desensitization to Violence').

The frequently observed short-term effects of arousal have led theorists to posit that some individual differences in the propensity to behave aggressively are related to individual differences in the propensity to become highly aroused and experience negative affect. Berkowitz (1993), Caprara (Caprara et al., 1985), Eisenberg (Eisenberg, Fabes, Nyman, Bernzweig, \& Pinuelas, 1994), and Strelau (1982), among others, have suggested that individuals who are "quick to anger," "often in bad moods," and have difficulty "controlling their emotions" are more at risk for behaving aggressively. Implied but unsaid in a lot of this discussion has been the point that such individuals are more at risk particularly for hostile, emotional, reactive aggression, rather than for instrumental, proactive aggression. Significant empirical evidence has also accumulated that supports this individualdifference perspective on high reactivity or arousability (Berkowitz, 1993).

Individual-difference research has also revealed, however, what might at first seem to be a paradoxical finding about reactivity or arousability. Substantial evidence now exists that those males who are characteristically lower in baseline arousal are more likely to behave aggressively and antisocially over a period of time. For example, Raine and colleagues (Raine, Reynolds, Venables, \& Mednick, 1997; Raine, Venables, \& Williams, 1990) found in a longitudinal study of males from age 15 to 29 that those who at 15 had lower baseline heart rates, lower baseline skin conductance, and lower baseline EEG activation were significantly more likely to be arrested for a crime in the next 14 years. The psychological concept of psychopathy includes as a major element low reactivity (Hare, 1965, 1978), and psychopathy and low reactivity (particularly low electrodermal reactivity to aversive stimuli) have been shown to relate significantly to antisocial and aggressive behavior (Fowles, 1993; Lykken, 1995) though not particularly to violent behavior. The puzzle about these results, of course, is that no similar situational effects of lower emotional arousal causing increased aggression have been found in experimental studies.

A number of explanations have been offered to explain the relation between low arousal or reactivity and antisocial and aggressive tendencies. Three major hypotheses have been offered to explain why low reactivity might be related to antisocial and aggressive behavior. Perhaps the most widely cited have been the "poor conditioning" theories that have argued that low reactivity or arousability makes conditioning difficult and therefore makes appropriate socialization less likely (Eysenck, 1997). Another alternative has been the sensationseeking theory that holds that individuals who are characteristically below their optimal level of arousal engage in antisocial and aggressive behavior for the "thrills" in order to raise their arousal level to a more "pleasant" place (Zuckermann, 1979). Still a third theoretical explanation is provided by the social-cognitive information-processing model described above (Huesmann, 1988, 1998). According to this model an individual's evaluation of a potential social script includes an evaluation of the emotions that are likely to result. Will it be an unpleasant experience or a pleasant experience? If a person experiences negative affect and 
arousal when thinking about the script and its outcome, its use will be inhibited. Consequently, those individuals who experience less "anxious arousal" at thoughts of aggression are more likely to use aggressive scripts to solve social problems.

This third theory differs from the other two in that it suggests that aggressive behavior is related not only to low reactivity or arousability in general but also specifically to low negative emotional reactivity to thinking about aggression. Lower baseline arousal is related to more aggression because lower baseline arousal translates into lower anxious arousal in response to thoughts of violence. However, individuals with average or even above-average baseline arousal who also experience lower anxious arousal to thoughts of aggression would also display more aggressive behavior according to this theory. This social information-processing theory also neatly explains how increased tendencies to become angered can result from repeated exposures to highly provoking scenes. The emotional reaction produced by attributions about the scene in the initial phase of information processing becomes associated with social and contextual cues present in the scene through classical conditioning. Subsequently the cues prime the reactions and probably the attributions as well, thereby making violence more likely.

\section{EMOTIONAL DESENSITIZATION TO}

VIOLENCE

Emotional desensitization is the name given to the habituation process through which repeated exposures to violence hypothetically cause a reduction in the observer's emotional reactions to violence. Desensitization to violence is seen as a natural, very subtle, and unconscious process, which occurs as an effect of repeated exposure to violent stimuli - real-life violence or filmed violence - and results from the habituation learning process. Habituation of neurophysiological responses over time is a well-established psychological phenomenon (though some responses resist habituation; for a review, see McSweeney \& Swindell, 2002). Repeated presentation of the same stimulus usually results in smaller and smaller neurophysiological responses to that stimulus. Systematic desensitization procedures, based on this neurophysiological process, are highly successful in the treatment of strong unpleasant feelings typical of phobias (e.g., Bandura \& Adams, 1977; Wolpe, $1958,1982)$ and other anxiety or fear disorders (e.g., Pantalon \& Motta, 1998). For example, systematically exposing someone with a snake phobia to snakes (initially under conditions designed to minimize anxiety and later under more anxiety-producing conditions) reduces the original anxiety reactions to such an extent that the person is no longer snake phobic. One feature of modern systematic desensitization treatments is to have the phobic person observe other people (live or filmed) successfully interacting with the feared stimulus (Bandura, Grusec, \& Menlove, 1967; Bandura \& Menlove, 1968). However, the term "desensitization" has been employed in so many different ways that the exact meaning of any particular usage can be quite unclear.

In our usage emotional desensitization to violence is understood as a decrease in both the physiological markers of the emotional arousal normally associated with fight/flight mobilization (e.g., decreases of electric skin conductance, heart rate and blood pressure) and a change in the cognitive interpretations of that arousal. The reactivity becomes gradually smaller with repeated exposures. This means that the organism is building up an emotional tolerance to violence in general or at least to an observed kind of violence. When this process being considered is a single response to a repeating single stimulus, the term "emotional habituation" is usually used. But when the process being considered is the emotional response to a repeating complex set of stimuli over a long run and in a broader context, the term "emotional desensitization" becomes more appropriate. Emotional desensitization thus refers to the joint processes of habituation of many characteristics of a complex stimuli that normally elicit strong emotional reactions.

In summary, we suggest that the label emotional desensitization to violence should be 
reserved to refer to a reduction in distressrelated physiological reactivity to observations or thoughts of violence (Carnagey, Bushman, \& Anderson, 2005). Emotional desensitization occurs when people who watch a lot of media violence no longer respond with as much unpleasant physiological arousal as they did initially. Because the unpleasant physiological arousal and negative emotional reactions normally associated with violence have an inhibitory influence on thinking about violence, condoning violence, or behaving violently, emotional desensitization - the diminution of the unpleasant arousal - can result in a heightened likelihood of violent thoughts and behaviors.

\section{Empirical Evidence That Exposure to Violence Increases Risk for Violence}

Having presented the underlying theory that explains the various psychological processes that explain why exposure to violence should increase violent behavior, let us now turn to a review of empirical evidence. As many fine recent reviews have covered the empirical evidence in great detail (Anderson et al., 2003; Anderson \& Bushman, 2001; Huesmann, Moise, \& Podolski, 1997; Paik \& Comstock, 1994; Savage, 2004), we focus here only on a few classic studies and some more important recent studies.

It is also important to note again that we have defined violent behavior as serious physical aggression intended to harm someone. Such aggression might fit into a category of criminal behavior or it might not, and, if it did fit into a category it might be reflected in criminal statistics or it might not. In other words, the question of whether observation of violence increases the risk of criminally violent behavior is a related but different question that in many respects is more difficult to test because of the low frequency of arrests and convictions for criminally violent acts. For example, Savage (2004) concluded that the evidence to date has not proved that viewing violence causes criminal behavior. Although we do not agree with many ele- ments of her review (which pays little attention to psychological theory), and although we believe that exposure to violence does cause increases in crime, the overall conclusion that it is unproven to date is probably fair. One can demonstrate that exposure to violence causes increased risk for aggression and increased risk for seriously violent behavior and still not be able to prove that it causes more crime.

\section{Copycat Crimes, Imitation, and Priming}

Jason V. Bautista, 20, and his 15-yearold half brother, Matthew Montejo, are accused of killing Jane M. Bautista, cutting off her head and hands and dumping her body along the Ortega Highway in Mexico. Jason Bautista told investigators he saw the same type of mutilation depicted in an episode of "The Sopranos," an HBO series about a Mafia family.

As reported on the British TV show Panorama, a Utah teenager kills his mother and half-sister in a fit of rage and then drives around with a friend talking about it and listening to the sound track from Oliver Stone's movie, Natural Born Killers. He has the video for the movie and has watched it over and over.

In December 1997 Michael Carneal of Kentucky opened fire on classmates after a prayer meeting in his high-school lobby, killing three and wounding five. Carneal, later sentenced to life in prison, told detectives he was imitating a scene he believed to be in the film, The Basketball Diaries.

A teenager who is arrested for delinquency and taken to a police station suddenly grabs an officer's gun, shoots him, walks down the corridor of the station shooting others systematically, steals a police car, and races away. The scene closely mimics a scenario from the video game Grand Theft Auto, which he has been playing over and over.

A 7-year-old in Texas has been watching wrestling on television when he turns away from the TV and, mimicking a move he has just seen, runs at his 3-year-old brother with his arm extended, hits him in the neck, and kills him. 
A gang of girls on a California beach who have just seen the movie Born Innocent in which a girl is raped with a broomstick assault another girl they encounter on the beach and rape her in the same way.

A young man robs a fast-food restaurant in Sault Lake City and forces the workers into a back room where he pours Drano down their throats just as a robber did in the Clint Eastwood movie he just saw.

In January 1998 in California Gina Castillo was stabbed 45 times by her son and another teenage boy. In court, a witness testified the boys were obsessed with Scream, a film with a knife-wielding villain.

These and other widely reported anecdotal stories of "copycat" crimes provide poor scientific evidence of any relation between exposure to media or game violence and violent behavior. For every copycat, there are large but unknown numbers of people who were exposed to the same crime or played the same game but did not then do anything similar. Nevertheless, these anecdotal cases make powerful, compelling, and suggestive examples. Furthermore, some systematic studies of criminal populations have indicated that significant numbers of criminals report that they got their ideas for violent crimes or were stimulated toward a crime by something they saw in the mass media. For example, Surette $(2002)$ reports that among a sample of "serious and violent juvenile offenders" incarcerated as adults, somewhere between $25 \%$ and $33 \%$ reported that they have "tried the same crime they saw in the media," "gone out looking to get into a fight" after watching a particular program, or "wanted a gun after seeing a gun used" in a show. Similarly, systematic studies of media news reports of suicides have shown that there is a real "Marilyn Monroe" effect in which copycat suicides occur shortly after highly publicized suicides. Phillips (1979) in a statistical analysis of suicide and automobile accident rates showed that a likely copycat effect occurs after highly publicized suicides for perhaps 2 weeks. In addition, scholarly case studies of individual violent offenders have often shown how observation of violent lifestyles in the movies or around them has provided the youth with validation for their own lifestyles (e.g., see Coleman, 2002) and made continuation of their violence more likely.

But perhaps the most important role that such anecdotal instances can play is to illustrate some of the psychological processes described above that are involved in media effects but about which many criminologists and the general public are underinformed. Violent copycat crimes by definition occur "shortly" after the perpetrator sees a crime. Thus, it is the short-term psychological processes that are most relevant. Yes, there are certainly predisposing individual differences that make one person more likely to copy and carry out a crime than another, but the effect of witnessing a crime on committing a crime shortly afterward can best be viewed as a precipitating situational effect.

Priming and simple imitation are undoubtedly the major processes in this regard. The young boy watching wrestling simply immediately imitates what he sees on the closest target - his young brother. When the crime situation is more removed from the scene being copied, usually elements of the situation activate memories of the violent scene including scripts for behaving, and these memories and activated scripts guide the criminal's behaviors. Thus the boy robbing the fast-food store sees the can of Drano, which primes memories of the film seen and gives him the idea of poisoning the workers with it. The depressed individual has the idea of suicide primed by hearing about a recent suicide, and the method for doing it is primed by the same story. The youth who is filled with rage at his parents has ideas of killing them primed by seeing movies like Natural Born Killers and then imitates an activated script from that movie in carrying out the murder.

Should we say in such cases that seeing the film or video game "caused the crime?" Certainly seeing the film or video game was not a necessary or sufficient condition for the perpetrator committing the crime. Many others saw these films or played these games 
and did not commit crimes, and many others committed similar crimes without seeing similar films or playing similar games. Yet, it seems likely that seeing the film or video game was a precipitating factor for the particular perpetrators in question. Given our understanding of the social-cognitive psychological processes involved in social behavior, the most reasonable hypothesis would seem to be that an accumulation of predisposing factors in these individual perpetrators put them in a state in which the criminal behavior could be triggered by the exposure. Therefore, the exposure was one of the causes of the behavior for these individuals. However, a more general conclusion about the causal role of exposure to violence in promoting violent behavior must depend on more rigorous scientific studies, including experiments, one-shot observational studies, and longitudinal observational studies.

\section{Experiments on Imitation and Priming}

Ever since Bandura's classical early studies on imitation of film violence (Bandura, Ross, \& Ross, 1961), experiments have played an important role in establishing that exposure to violence in the short run causes increases in immediate aggressive behavior. There can no longer be any dispute about this conclusion, and more recent studies than those of Bandura have dealt with more externally valid measures of serious aggressive or violent behavior.

Josephson (1987), for example, randomly assigned 396 seven- to nine-year-old boys to watch either a violent or a nonviolent film before they played a game of floor hockey in school. Observers who did not know what movie any boy had seen recorded the number of times each boy physically attacked another boy during the game. Physical attack was defined to include hitting, elbowing, or shoving another player to the floor, as well as tripping, kneeing, pulling hair, and other assaultive behaviors that would be penalized in hockey (the only verbal act included in the measure was insulting another player with an abusive name). One added element in this study was that a specific cue that had appeared in the violent film (a walkie-talkie) was carried by the hockey referees in some conditions. This particular cue presumably reminded the boys of the movie they had seen earlier. Josephson found that for aggressive boys (those who scored above average on a measure of aggressiveness), seeing a violent film prior to playing increased the likelihood of aggression, and the combination of seeing a violent film and seeing the movieassociated cue stimulated significantly more assaultive behavior than any other combination of film and cue. This is a classic confirmation of a priming effect coupled with an observational learning effect.

Two related randomized experiments demonstrated that exposure to violent media violence can lead to increased physical assaults by teenaged boys, at least in the short run. In a home for delinquent boys in Belgium, Leyens, Camino, Parke, and Berkowitz (1975) assigned boys in two cottages to see violent movies every night for 5 nights while boys in the other two cottages saw nonviolent films. The boys were observed interacting after the movies each evening and were rated for their frequency of hitting, choking, slapping, and kicking their cottage mates. Those boys who were exposed to the violent films engaged in significantly more physical assaults $(p<.025)$ on their cottage mates during the week of viewing, most likely because aggressive ideas and scripts were primed by the films. Quite probably among these boys aggressive scripts were already well learned and were not "acquired" from the film. Rather these existing scripts were primed by the film and thus more readily employed when they felt provoked in some way.

\section{Experiments on Emotional Desensitization}

Some experiments have also provided support for more long-term processes. In particular several studies have shown how youth who watch violence become more tolerant of violence (cognitive desensitization) and experience less arousal to violence (emotional desensitization). For example, in 
studies with young children (Drabman \& Thomas, 1974, 1975; Thomas \& Drabman, 1975), both boys and girls who were shown a brief violent film clip were slower to call an adult to intervene when they saw two younger children fighting than were peers who had watched a neutral film. The single violent clip appeared to make the children more tolerant of aggression, at least temporarily. Furthermore, the children who saw the violent film showed less physiological reactivity to seeing children fighting (Molitor \& Hirsch, 1994; Thomas, Horton, Lippincott, \& Drabman, 1977). Similarly, Malamuth and Check (1981) found an increased acceptance of physical aggression toward women by college men several days after they had watched violent sex scenes. Linz (1988) and colleagues report similar findings of desensitization to violent 'slasher' films.

\section{Cross-Sectional Surveys Suggesting Observational Learning or Desensitization Effects}

Although the experimental studies have shown unequivocally that exposure to media violence increases the risk for aggressive behavior in the short run, they have two major limitations. First, experiments cannot be used to investigate long-term effects very well. Second, the criterion measures of aggression in experiments have not been and cannot ethically be representative of the serious physical aggression that really harms the target of the aggression (i.e., violent aggression). However, both of these deficiencies have been remedied in recent years with the publication of a variety of cross-sectional surveys and longitudinal studies. The crosssectional surveys add to the external validity of the laboratory experiments by investigating "real" violence. The longitudinal studies add to the external validity of experiments as well, but also extend the investigation to long-term effects of exposure to violence.

Cross-sectional surveys over the past 40 years have consistently provided evidence that the current physical aggression, verbal aggression, and aggressive thoughts of young people are correlated with the amount of television and film violence they regularly watch (see reviews by Chaffee, 1972; Comstock, 1980; Eysenck \& Nias, 1978 ; and Huesmann \& Miller, 1994). Moreover, the studies reporting significant correlations have used a variety of research methods and examined youngsters of different ages and from different cultures (e.g., Huesmann \& Eron, 1986). In some studies, the aggression assessed has included physically aggressive acts serious enough to fit our definition of violence. For example, McLeod, Atkin, and Chaffee (1972) studied the correlations between "aggressive behavioral delinquency" (fighting, hitting, etc.) and TV violence viewing in samples of Wisconsin and Maryland high-school and junior-high-school students. They found significant correlations ranging from $.17(p<.05)$ to $.28(p<.01)$ for both males and females. In a study of English $12-$ to 17-year-old males, Belson (1978) reported $49 \%$ more violent acts in the past 6 months by heavy TV violence viewers than by light violence viewers.

Paik and Comstock's (1994) meta-analysis also examined cross-sectional surveys. For 410 tests of the hypothesis that viewing television violence is positively correlated with aggressive behavior, they reported an average $r$ of .19. These authors identified 200 tests of the hypothesis in which the dependent measure of aggressive behavior was physical aggression against another person. The effect size was essentially the same for these studies as for all surveys combined (i.e., $r=.20$ ).

These cross-sectional surveys provide convincing evidence that frequent viewing of violence in the media is associated with comparatively high levels of aggressive behavior. The data from these surveys are consistent with the causal conclusions of experiments, though they do not really add to our certainty about the processes involved. The relations found in surveys cannot be due to simple short-term imitation, or excitation transfer, or immediate priming of aggressive thoughts and behaviors; instead, they must be due to long-term processes, such as complex observational learning and desensitization. The best evidence 
these surveys have shown that is consistent with such hypothesized long-term processes is that aggressive cognitions, different emotional reactions to violence, and aggressive behavior have all been found to be more prevalent among those who are regularly exposed to more violence.

\section{Longitudinal Studies, Observational Learning, Desensitization, and Justification}

Now let us turn to the longitudinal studies that have directly investigated the long-term effects of media violence. Although these studies also cannot by themselves unequivocally demonstrate causation, they do provide more evidence than cross-sectional studies about the relative plausibility of several alternative causal models and processes.

A significant number of longitudinal studies now exist, and most have been reviewed in other places in more detail than we review them here (e.g., Anderson et al., 2003; Huesmann et al., 1997). Most of these studies focus on exposure to television and films, as few longitudinal studies on violent video games have yet been completed. These studies uniformly reveal longitudinal correlations between early habitual exposure to media violence and later aggressive and violent behavior. The one meta-analysis separating out longitudinal studies (Anderson \& Bushman, 2001) found a statistically significant average effect size of .17 across 42 independent tests involving almost 5,000 participants.

In perhaps the first longitudinal study on this topic, initiated in 1960 in New York State, Eron, Huesmann, Lefkowitz, and Walder (1972) found that boys' early childhood viewing of violence on TV was statistically related to their aggressive and antisocial behavior 10 years later (after graduating from high school), even controlling for initial aggressiveness, social class, education, and other relevant variables (Lefkowitz, Eron, Walder, \& Huesmann, 1977). On the other hand, behaving aggressively in middle childhood did not predict higher subsequent viewing of violence, making it implausi- ble that the correlation was due to aggressive children turning to watching more violence. A 22 -year follow-up of these same boys revealed that their early aggression predicted later criminality at age 30 and that early violence viewing also was independently but weakly related to their adult criminality (Huesmann, 1986, 1995, 2004). Even more recently, data collected when the participants were 48 years old have shown a correlation between TV violence exposure 40 years earlier at age 8 and aggression of several types at age 48 (Huesmann, 2004). None of these data provide any evidence that those boys who are more aggressive turn to watching more violence either because it justifies their behavior or for another reason.

Shortly after this first study was started, Milavsky, Kessler, Stipp, and Rubens (1982) conducted a longitudinal study (funded by NBC) of boys and girls aged 7 to 15 from two Midwestern cities. They examined the effects of television violence on aggression using measures that included serious physical aggression and delinquency. The youth were surveyed up to five times during a 3-year period (1970-1973). Cross-sectional correlations between viewing of TV violence and concurrent levels of aggression ranged from .13 to .23 for boys and .21 to .37 for girls. The investigators then examined the longitudinal regressions predicting aggressive behavior at one point in time from TV violence viewing at an earlier time, while statistically controlling for earlier aggression. They examined these regressions over 15 intervals ranging from 5 months to 3 years apart. For elementary-school boys, 12 of the 15 regression coefficients were positive, although only 2 were statistically significant. Ten of the 15 coefficients were positive for girls, although only 3 were statistically significant. A comparable analysis carried out in a subsample of teenaged boys showed a positive correlation in six of eight cases, but only one such "lag" yielded a significant effect. In all cases, adding SES as a covariate reduced the significant effects further. However, it should be noted that these predictive analyses were based on subsamples from which the research team had deleted the data of 
many of the most aggressive children $(25 \%$ of boys and $16 \%$ of girls in the initial sample), because they supposedly had not reported their TV viewing accurately.

More recently Huesmann and colleagues have completed a longitudinal study in which serious physical aggression and violence in young adulthood were related to habitual exposure to TV violence 15 years earlier (Huesmann et al., 2003). Among the sample of 329 young adults from the Chicago area, the researchers found significant correlations between television violence viewing during childhood and physical, verbal, and indirect aggression during young adulthood, for both men $(r=.21$, $n=153, p<.01)$ and women $(r=.19$, $n=176, p<.01)$. When the outcome examined was restricted to physical aggression or violence (e.g., punch, beat, choke, threaten, or attack with a knife or gun), the correlations were still significant $(\underline{r s}=.17$ and .15 , respectively). Furthermore, when the people who had watched violent programs frequently in childhood were compared with their counterparts who viewed these programs much less often, it was found that the former, as adults, committed significantly more acts of physical aggression, such as having "pushed, grabbed, or shoved their spouses" (p. $210 ; 42 \%$ vs. $22 \%$ in the case of males) or "shoving, punching, beating or choking" ( $p .210$ ) someone who had made them angry ( $17 \%$ vs. $4 \%$ for females). Additionally, structural modeling analyses showed that, although high aggressiveness during childhood was related only slightly and not significantly to viewing television violence later in life, habitual exposure to TV violence during childhood predicted significantly higher levels of serious aggressive behavior even 15 years later. This longitudinal effect remained significant even when the researchers controlled statistically for parents' education, child-rearing behaviors, aggression, and many other factors, as well as the children's academic achievement. The boys and girls who watched more TV violence consistently when they were between 6 and 10 years old grew up to be more seriously aggressive when they were 21 to 25 years old, independently of how aggressive they were initially. In this study comparable data were collected in three other countries Finland, Poland, and Israel. Although analyses of the data from the other countries are not yet completed, preliminary results indicate that childhood exposure to media violence also predicts adult aggression in males and females in Finland and in males in Israel, but not in Poland, where the social transition of the 1980 s seems to have changed the relations (Huesmann, 2006; Huesmann \& Moise-Titus, 1999; Viemero, 2002).

One other very important finding from this study was that adult normative beliefs about the acceptability of aggression were significantly related both to exposure to violence 15 years earlier and to concurrent adult aggression (Huesmann, 2006; Huesmann \& Moise, 1999). In support of our conception that social cognitions such as normative beliefs are acquired though observational learning and mediate the long-term effects of exposure to violence, it was shown that the mediating effect of such normative beliefs can explain a significant part (but not all) of the long-term relation between childhood exposure and adult aggression.

Johnson and his colleagues (Johnson, Cohen, Smailes, Kasen, \& Brook, 2002) conducted another recent longitudinal study that examined the effects of TV habits in adolescence and early adulthood on later violent behavior. They found that in their sample of over 700 youth TV exposure at age 14 significantly predicted selfreported assault and fighting behavior at 16 or 22 years of age (particularly for males), even after controlling statistically for family income, parental education, verbal intelligence, childhood neglect, neighborhood characteristics, peer aggression, and school violence. In addition, time spent on TV viewing at age 22 was associated with subsequent assaults or fights resulting in injury in males and females and additionally with subsequent aggressive behavior of any kind and robbery, threats to injure, or use of a weapon to commit a crime. Unfortunately, the only measure of media exposure was total viewing time, with no data being 
collected on the content viewed. Consequently, the mechanisms that might explain these results remain unclear. It is possible that those with greater overall exposure to the mass media also had greater exposure to violence in the mass media. However, it is also possible that the effects could be due to a "passive" process in which the time spent viewing the mass media detracts from better uses of time that promote nonaggressiveness.

An even larger longitudinal sample was surveyed recently by Slater and his colleagues (Slater, Henry, Swaim, \& Anderson, 2003). They interviewed over 2,500 middleschool students over 2 years. Although their aggression measure did not assess particularly serious violence, they found compelling evidence of an effect of media violence on aggression. Using hierarchical linear growth curve modeling with imputations of missing data, they found a significant lagged effect of prior violence viewing on subsequent aggression, but no significant effect of prior aggression on subsequent violence viewing.

A very similar analysis technique was used by Guerra, Huesmann, and Spindler (2003) to demonstrate a longitudinal effect of exposure to neighborhood violence on serious aggressive behavior in children. As we said earlier in this chapter, the theory for how exposure to violence affects aggressive behavior does not distinguish between whether the violence is observed in the streets outside a child's house or on the TV. In this particular study over 4,000 children's exposure to neighborhood violence was assessed each year as they progressed from the first to sixth grade. The children all lived in high-violence neighborhoods in the Chicago area. The hierarchical linear growth curve model that fit the data showed that exposure to neighborhood violence in one year had a significant effect on the child's aggression in the next year, even after controlling for the prior level of aggression. However, the child's aggression did not affect how much violence they would see in the next year after one controlled for the violence they saw in the current year. There was no evidence at all of more aggressive children being more likely to be exposed to neighborhood violence.

Finally, in the one published longitudinal study on video games, Ihori, Sakamoto, Kobayashi, and Kimura (2003) studied Japanese fifth and sixth graders at two points in time separated by 4 to 5 months, measuring overall video game exposure rather than exposure to violent video games. They reported that the amount of exposure to video games was positively (and significantly) related to later levels of violent physical behavior after controlling for earlier violent behavior.

These longitudinal studies provide compelling evidence of a lasting effect of the regular observation of violence in childhood on serious aggressive behavior later in life. Furthermore, these studies contradict the theory that the correlation between exposure to violence and actual violent behavior is entirely due to more violent people liking to watch more violence. People indeed may justify their own behavior by turning to watching more violence in the media, but that effect cannot explain the data found in the several studies that have examined such a process (e.g., Guerra et al., 2003; Huesmann et al., 2003; Slater et al., 2003). When the longitudinal evidence is coupled with the experimental evidence presented earlier, the case for a lasting causal effect for exposure to violence on violent behavior seems more than just plausible. The longterm effect can be explained theoretically by the changes in cognitions and emotions that are engendered by exposure to violence and then persist for a long time. However, the amount of evidence demonstrating that such cognitive changes or emotional changes do indeed mediate the effect is still limited.

\section{Moderators of the Long-Term Effects of Exposure to Violence}

We did not devote much space above to a discussion of all the factors that moderate the long-term or short-term impact of observed violence on aggressive and violent behavior in the observer. Yet, the effects are 
clearly moderated by a very large number of factors, including characteristics of the viewer, the observed violence scene, and the setting in which the scene is viewed. For example, with regard to the person, genetic, personal, familial, community, and cultural factors all can moderate the effect. Not every child who is exposed to violence will behave noticeably more aggressively, even if they are affected to some extent. Most children are highly resilient, and it requires a convergence of many bad things to make them seriously "bad."

We began this analysis by noting in our theoretical model that observation of violence is just one factor among many predisposing and precipitating factors that combine to influence aggressive and violent behavior. These factors do not simply combine additively. They combine interactively. Thus, it is easier to talk about some of the factors that do not seem to play important moderating roles than to talk about factors that do play important roles. The most important moderating factors have been discussed in detail in several recent reviews (Anderson et al., 2003; Bushman \& Huesmann, 2002; Huesmann, Moise, \& Podolski, 1997), and we only summarize a few of their conclusions here. For example, identification with the aggressive perpetrator is a very important moderator of the effects, as are the extent to which the violence (1) seems true to life, $(2)$ is portrayed as justified, and ( 3 ) is perceived as rewarded. Thus, one can expect first-person shooter games to have larger effects than third-person games, though this has yet to be confirmed. At the person level, the most aggressive behaviors will come from exposing already aggressive individuals to more violence, though exposure affects even nonaggressive individuals. Children experience more lasting effects than adults. Although children with lower IQs and lower SES are both exposed to more violence and behave more aggressively, exposure seems to affect children on all levels of these factors. Finally, the effects seem to be less for children whose parents co-view with the child and discuss with the child what they are seeing (i.e., engage in parental mediation; Nathanson, 1999).

\section{Empirical Data on Emotional Reactions to Violence}

As outlined earlier in this chapter, the longterm effects of exposure to violence are viewed as due either to changes in cognitions, such as social scripts, world schemas, and normative beliefs, or to changes in emotional reactions to violence.

Of course, experiencing more anger in response to certain stimuli can increase the risk for aggressive behavior, so being sensitized to experience more anger should certainly increase the risk for aggression. In fact, some recent research has indicated that those who experience more anger when observing others being provoked are more at risk for reactive aggression (Huesmann, Moise, \& Kirwil, 2004; Moise-Titus, 1999). However, there is little empirical research showing how repeated exposures to violence sensitize people to experience more anger, even though the theory is very plausible.

The other long-term emotional change that we linked theoretically above to increases in violent behavior is a decrease in negative emotional reactions to observing or thinking about violence. When there is little negative emotional reaction to thoughts of violence, the evaluation of violent outcomes looks more positive, and violent behavior becomes more likely. In this final section of the chapter we want to discuss some quasiexperimental studies that provide particular evidence consistent with the two parts of this theoretical proposition: (1) that negative emotional reactions to scenes or thoughts of violence diminish with repeated exposures to violence and (2) that diminished negative emotional reactions to violence increase the risk for violent behavior.

With regard to the first part of this proposition, research has indeed shown that violent scenes are less unpleasantly arousing to those who have observed more of them (Cline, Croft, \& Courrier, 1973; Oliver, 2004), and even relatively brief observations 
of media violence (or real-life violence) can reduce subsequent physiological reactions to the sight of real-world violence (Carnagey et al., 2005; Kirwil, 2002a; Moise-Titus, 1999; Molitor \& Hirsch, 1994; Thomas et al., 1977). Such desensitization occurs for violent video games as well as films and can be detected in EEG changes as well as skin conductance (Bartholow et al., 2006). Desensitization occurs in children and adults, though the course of habituation for adult females may be slower (Kirwil, 2004a; Thomas et al., 1977). Emotional desensitization to observed aggression in children has also been related to more tolerance for aggression on children's parts (Thomas \& Drabman, 1975). Viewing media violence can elicit strong emotions, such as fear or anger, but these emotions are usually temporary immediate reactions of relatively short duration and accompanied by increase in physiological arousal (Cantor, 2002; van der Voort, 1986). It has to be pointed out that emotional responses to such complex stimuli as filmed violence are composed of various basic emotions, usually negative in emotional tone, such as anxiety, distress, disgust, sadness, or empathy toward the victim or hate toward the perpetrator (Kirwil, 2002 b). Emotional desensitization to observed violence takes place after repeated exposure to violence, when there is blunting of these emotional reactions to events or stimuli that normally elicit strong emotional responses in the observer. This means that frequent observers of violence became gradually less and less emotionally sensitive to acts of violence and they become less quickly frightened or angered or disgusted by violent scenes (Cantor, 2002, 2003; Kirwil, 2002 b; Oliver, 2004).

Research has also shown that affective habituation may occur to subliminal exposure to extreme stimuli (violent stimuli are one of the kind of extreme negative stimuli) and that the size of the desensitization effect might be a direct function of how extreme the stimuli are (Dijksterhuis \& Smith, 2002). The more intense the stimuli are, the more pronounced is the decrease in intensity of negative affective reactions toward violence.
Consequently, the extreme negative violent stimuli became subjectively less extremely negative. As a result "initially strong excitatory reactions have become weak or have vanished entirely with repeated exposure to stimuli of a certain kind (very violent stimuli); and correspondingly, initially strong affective reactions have been blunted" (Zillmann, 1982, p. 61).

The second part of the proposition, that those who show diminished emotional reactions to violence behave more aggressively, has now also been confirmed with recent studies. In a quasi-experimental study Moise-Titus (1999) demonstrated that college males who displayed less anxious arousal (as measured by skin conductance and self-reports of emotions) when watching extremely violent and gory scenes of violence (e.g., scenes from Reservoir Dogs) had engaged in more physical aggression in the past and were more physically aggressive toward another student immediately after watching the film than were those who showed more anxious arousal to the violence. Kirwil and Huesmann followed this study with a series of studies that replicated and elaborated the results. They showed that more aggressive male college students show decreased arousal to repeated scenes of violence (i.e., they habituate faster physiologically to observed violence than do less aggressive male college students; Huesmann et al., 2004; Kirwil, 2002a, 2004a; Kirwil \& Huesmann, 2003) and that this effect of faster diminishing physiological responses occurs in U.S. and Polish males (Kirwil, $2002 \mathrm{a}$ ). However, similar to earlier findings reported by Thomas et al. (1977), Kirwil (2004a) found that these differences did not occur for females. Females, on the whole, showed much greater negative emotional reactions when observing males brutally attacking other males than did the males, and the most aggressive females (particularly reactively aggressive females) displayed more (not less) emotional arousal than other females when observing these scenes. These results from the Kirwil (2004a) and Thomas et al. (1977) studies suggest that sensitization to provocation may be 
a more important emotional consequence of observing violence for females than is desensitization.

The desensitizing effects of exposure to violence on males and the relation of males' diminished reactions to violence to their aggressiveness appear to be fairly robust, however. For example, in addition to her findings with college males, Kirwil (2004b) also found a relation between diminished emotional reactions to observed violence and the extent to which policemen had been exposed to real-life violence. In particular, it was shown that Polish riot policemen, who are exposed to violence in their job, habituate physiologically to filmed violence faster than college students and show less arousal on the average. Furthermore, the magnitude of this decreased arousal in policemen depends on how long they have been policemen (Kirwil 2004b; Kirwil \& Huesmann, 2003). Decreased emotional responses to observed violence have also been linked to more aggression in clinically aggressive boys. In a study comparing 59 boys diagnosed with Disruptive Behavior Disorder (DBD) with 44 normal boys, Grimes, Berger, Nochols, Vernberg, and Fonagy (2004) found almost identical results. When observing violent films clips, these DBD boys responded with significantly less physiological arousal (skin conductance level and vagal tone) than did the normal boys.

It seems clear, then, that decreased arousal in response to seeing or thinking about violence is a predictor or risk for behaving violently and that repeated exposure to violence decreases negative emotional (and cognitive) reactions to violence. However, three important related questions remain unanswered. First, is the relation between lack of a negative affective response to violence and risk for violent behavior simply an instance of a more general phenomenon that low arousal is a predictor of aggression? Or is the relation at least partially specific to exposure to violence? Second, is the lack of a negative emotional response predictive of all kinds of violence or only of proactive, nonemotional, violent behavior? Third, are the individual differ- ences in emotional reactions to violence that have been observed in empirical studies innate, are they acquired through repeated exposures to violence, or are they some combination of the two? Much empirical evidence has been collected to test the hypothesis that violent offenders are predisposed to manifest aggression because of extreme characteristics of their emotional reactivity (i.e., overreactivity in the case of impulsive reactive aggression or underreactivity in the case of premeditated proactive aggression; for a review, see Raine, 1993; Raine et al., 2006) or fear deficit (Lykken, 1995). However, there is not much research demonstrating what impact repeated exposure to filmed violence has on experienced intensity and valence of arousal, as well as real violent behavior in offenders. Does repeated exposure to violence make only the predisposed violent offender more emotionally desensitized and more cruel? Or does exposure to filmed violence gradually desensitize any individual and make him or her more inclined to be aggressive and to commit violent offences? Quite likely, the dynamics of physiological arousal and emotions experienced by violent offenders under impact of repeated exposure differs depending on the kind of violent crime they have committed.

\section{Summary}

Severe violent behavior is almost always the product of predisposing individual differences and precipitating situational factors (Huesmann, 1998). One important environmental experience that contributes both to predisposing a person to behave more violently in the long run and to precipitating violent behavior in the short run is exposure to violence. Psychological theories that have emerged over the past few decades now explain the short-term precipitating effects mostly in terms of priming, simple imitation, and excitation transfer. However, the long-term predisposing effects involve more complex processes of observational learning of cognitions and of emotional desensitization or sensitization. In particular, we 
argue that anticipated emotional responses play an important role in the cognitive processing that controls violent behavior. Abnormal violent behavior is not viewed as a consequence of "deficient" processing, but as a consequence of "different" processing.

In this chapter these theories were elaborated, and the compelling empirical evidence in support of these theories from experiments and longitudinal field studies is reviewed. The experimental studies have demonstrated causation unambiguously. Quasi-experimental studies have shown that desensitization does occur and that people with lower negative affective responses to observing violence are more at risk for behaving violently. The longitudinal and cross-sectional field studies have shown that children and young adults who regularly are exposed to more media violence or real-world violence around them behave more aggressively both immediately and many years later (see Anderson et al., 2003). The effect sizes typically are not large - ranging from .15 to .30 - but are highly replicable and obtain in many different cultures with different media systems (Anderson et al., 2003; Anderson \& Bushman 2001; Huesmann, Moise, \& Podolski, 1997; Paik \& Comstock, 1994). They have been found for exposure to violent TV shows, for exposure to violent films, and for playing violent video games. Finally, they are as large as many other effect sizes that are considered to be public health threats.

Nevertheless, there are large holes in our knowledge of why and how exposure to violence stimulates violent behavior. The greatest need is for research that more specifically investigates links between media violence exposure and the more serious forms of aggression (e.g., criminally violent behavior), as well as links to theoretically relevant mediating variables. This need is best filled by research on high-risk populations, such as offender populations. This review also revealed a need for additional research on potential moderating factors (e.g., personal factors, family factors, and cultural factors) that determine who is more affected by observing violence. In sum, the proposed research is needed to provide a better estimate of the relative magnitude of media violence effects on serious violent and criminal behavior (relative to other risk factors), to identify populations most vulnerable to such media violence effects, and to provide a basis for sound public health policy regarding media violence.

\section{References}

Abelson, R. P. (1981). Psychological status of the script concept. American Psychologist, 36, 715729.

Anderson, C. A., Benjamin, A. J., \& Bartholow, B. D. (1998). Does the gun pull the trigger? Automatic priming effects of weapon pictures and weapon names. Psychological Science, 9, 308314 .

Anderson, C. A., Berkowitz, L., Donnerstein, E., Huesmann, L. R., Johnson, J., Linz, D., et al. (2003). The influence of media violence on youth. Psychological Science in the Public Interest, 4(3), 81-110.

Anderson, C. A., \& Bushman, B. J. (2001). Effects of violent video games on aggressive behavior, aggressive cognition, aggressive affect, physiological arousal, and prosocial behavior: A meta-analytic review of the scientific literature. Psychological Science, $12,353-359$.

Anderson, C. A., \& Huesmann, L. R. (2003). Human aggression: A social-cognitive view. In M. A. Hogg \& J. Cooper (Eds.), Handbook of social psychology (pp. 296-323). London: Sage.

Bandura, A. (1973). Aggression: A social learning theory analysis. Englewood Cliffs, NJ: Prentice Hall.

Bandura, A. (1977). Social learning theory. Englewood Cliffs, NJ: Prentice Hall.

Bandura, A. (1986). Social foundations of thought and action. Englewood Cliffs, NJ: Prentice Hall.

Bandura, A., \& Adams, N. E. (1977). Analysis of self-efficacy theory of behavioral change. Cognitive Therapy and Research, 1, 287-310.

Bandura, A., Grusec, J. E., \& Menlove, F. L. (1967). Vicarious extinction of avoidance behavior. Journal of Personality and Social Psychology, 5, 16-23.

Bandura, A., \& Menlove, F. L. (1968). Factors determining vicarious extinction of avoidance behavior through symbolic modeling. Journal of Personality and Social Psychology, 8, 99-108. 
Bandura, A., Ross, D., \& Ross, S. A. (1961). Transmission of aggression through imitation of aggressive models. Journal of Abnormal and Social Psychology, 63, 575-582.

Bandura, A., Ross, D., \& Ross, S. A. (1963a). Imitation of film-mediated aggressive models. Journal of Abnormal and Social Psychology, 66, 3-11.

Bandura, A., Ross, D., \& Ross, S. A. (1963b). A comparative test of the status envy, social power, and secondary reinforcement theories of identificatory learning. Journal of Abnormal and Social Psychology, 67, 527-534.

Bandura, A., Ross, D., \& Ross, S. A. (1963 c). Vicarious reinforcement and imitative learning. Journal of Abnormal and Social Psychology, $67,601-607$.

Bargh, J. A., \& Chartrand, T. L. (1999). The unbearable automaticity of being. American Psychologist, 54, 462-479.

Bargh, J. A., \& Pietromonaco, P. (1982). Automatic information processing and social perception: The influence of trait information presented outside of conscious awareness on impression formation. Journal of Personality and Social Psychology, 43, 437-449.

Bartholow, B. D., Bushman, B. J., \& Sestir, M. A. (2006). Chronic violent video game exposure and desensitization to violence: Behavioral and event-related brain potential data. Journal of Experimental Social Psychology, 42(4), 532539.

Bartholow, B. D., Anderson, C. A., \& Carnagey, N. L. (2005). Interactive effects of life experience and situational cues on aggression: The weapons priming effect in hunters and nonhunters. Journal of Experimental Social Psychology, 41(1), 48-6o.

Belson, W. A. (1978). Television violence and the adolescent boy. Hampshire, England: Saxon House, Teakfield.

Berkowitz, L. (1962). Aggression: A social psychological analysis. New York: McGraw-Hill.

Berkowitz, L. (1983). Aversively stimulated aggression: Some parallels and differences in research with animals and humans. American Psychologist, 38, 1135-1144.

Berkowitz, L. (1993). Aggression: Its causes, consequences, and control. New York: McGraw-Hill.

Berkowitz, L., \& LePage, A. (1967). Weapons as aggression-eliciting stimuli. Journal of Personality and Social Psychology, 7, 202-207.

Brass, M., \& Heyes, C. (in press). Imitation: is cognitive neuroscience solving the correspon- dence problem? Trends in Cognitive Sciences, 9(10), 489-495.

Bryant, J., \& Zillmann, D. (1979). Effect of intensification of annoyance through unrelated residual excitation on substantially delayed hostile behavior. Journal of Experimental Social Psychology, 15, 470-480.

Bushman, B. J., \& Huesmann, L. R. (2001). Effects of televised violence on aggression. In D. G. Singer \& J. L. Singer (Eds.), Handbook of children and the media (pp. 223-254). Thousand Oaks: Sage.

Cantor, J. (2002). The media and children's fears, anxieties, and perceptions of danger. In D. G. Singer \& J. L. Singer (Eds.), Handbook of children and the media (pp. 207-21). Thousand Oaks: Sage.

Cantor, J. (2003). Media violence effects and interventions: The roles of communication and emotion. In J. Bryant, D. RoskosEvoldsen, \& J. Cantor (Eds.), Communication and emotion (pp. 197-219). Mahvah, NJ: Erlbaum.

Caprara, G. V., Cinanni, B., D'Imperio, G., Passerini, S., Renzi, P., \& Travaglia, G. (1985). Indicators of impulsive aggression: Present status of research on irritability and emotional susceptibility scales. Personality and Individual Differences, 6, 665-674.

Carlson, M., Marcus-Newhall, A., \& Miller, N. (1990). Effects of situational aggression cues: A quantitative review. Journal of Personality and Social Psychology, 58, 622-633.

Carnagey, N. L., Bushman, B. J., \& Anderson, C. A. (2005). Video game violence desensitizes players to real world violence. Manuscript submitted for publication.

Chaffee, S. H. (1972). Television and adolescent aggressiveness (overview). In G. A. Comstock \& E. A. Rubinstein (Eds.), Television and social behavior: A technical report to the Surgeon General's Scientific Advisory Committee on Television and Social Behavior. Vol. 3: Television and adolescent aggressiveness (DHEW Publication No. HSM 72-9058, pp. 1-34). Washington, DC: U.S. Government Printing Office.

Cline, V. B., Croft, R. G., \& Courrier, S. (1973). Desensitization of children to television violence. Journal of Personality and Social Psychology, $27,360-365$.

Coleman, R. M. (2002). The Menace II Society copycat murder case and thug life: A reception study with a convicted criminal. In R. M. 
Coleman (Ed.), Say it loud! African-American audiences, media, and identity. New York: Routledge.

Comstock, G. (1980). New emphases in research on the effects of television and film violence. In E. L. Palmer \& A. Dorr (Eds.), Children and the faces of television: Teaching, violence, selling (pp. 129-148). New York: Academic Press.

Dautenhahn, K., \& Nehaniv, C. (2002). Imitation in animals and artifacts. Cambridge, MA: MIT Press.

Dijksterhuis, A., \& Smith, P. K. (2002). Affective habituation: Subliminal exposure to extreme stimuli decreases their extremity. Emotion, $2(3), 203-214$.

Dodge, K. A. (1986). A social information processing model of social competence in children. In M. Perlmutter (Ed.), The Minnesota symposium on child psychology (Vol. 18, pp. 77125). Hillsdale, NJ: Erlbaum.

Dodge, K. A. (1993). Social-cognitive mechanisms in the development of conduct disorder and depression. Annual Review of Psychology, $44,559-584$.

Drabman, R. S., \& Thomas, M. H. (1974). Does media violence increase children's tolerance for real-life aggression? Developmental Psychol$o g y, 10,418-421$.

Drabman, R. S., \& Thomas, M. H. (1975). Does TV violence breed indifference? Journal of Communication, 25, 86-89.

Eisenberg, N., Fabes, R. A., Nyman, M., Bernzweig, J., \& Pinuelas, A. (1994). The relations of emotionality and regulation to children's anger-related reactions. Child Development, $65,109-128$.

Eron, L. D., Huesmann, L. R., Lefkowitz, M. M., \& Walder, L. O. (1972). Does television violence cause aggression? American Psychologist, $27,253-263$.

Eron, L. D., Walder, L. O., \& Lefkowitz, M. M. (1971). The learning of aggression in children. Boston: Little, Brown.

Eysenck, H. J. (1997). Personality and the bio-social model of anti-social and criminal behaviour. In A. Raine, D. P. Farrington, P. O. Brennen, \& S. A. Mednick (Eds.), The biosocial basis of violence (pp. 21-37). New York: Plenum Press.

Eysenck, H. J., \& Nias, D. K. B. (1978). Sex, violence, and the media. New York: Saint Martin's Press.

Fadiga, L., Craighero, L., \& Olivier, E. (2005). Human motor cortex excitability during the perception of others' action. Current Opinion in Neurobiology, 15, 213-218.

Fiske, S. T., \& Taylor, S. E. (1984). Social cognition. Reading, MA: Addison-Wesley.

Fowles, D. (1993). Electrodermal activity and antisocial behavior: Empirical findings and theoretical issues. In J.-C. Roy, W. Boucsein, D. Fowles, \& J. Gruzelier (Eds.), Progress in electrodermal research (pp. 223-237). London: Plenum Press.

Fowles, J. (1999). The case for television violence. Thousand Oaks, CA: Sage.

Freedman, J. (2002). Media violence and its effect on aggression. Toronto: University of Toronto Press.

Gallese, V., Fadiga, L., Fogassi, L., \& Rizzolatti, G. (1996). Action recognition in the premotor cortex. Brain, 119, 593-609.

Geen, R. G., \& O'Neal, E. C. (1969). Activation of cue-elicited aggression by general arousal. Journal of Personality and Social Psychology, 11, 289-292.

Grimes, T., Berger, L., Nochols, K., Vernberg, E., \& Fonagy, P. (2004). Is psychopathology the key to understanding why some children become aggressive when they are exposed to violent television programming? Human Communication Research, 30, 153-181.

Guerra, N. G., Huesmann, L. R., \& Spindler, A. J. (2003). Community violence exposure, social cognition, and aggression among urban elementary-school children. Child Development, 74(5), 1507-1522.

Hare, R. D. (1965). A conflict and learning theory analysis of psychopathic behavior. Journal of Research in Crime and Delinquency, 12-19.

Hare, R. D. (1978). Electrodermal and cardiovascular correlates of psychopathy. In R. D. Hare \& D. Schalling (Eds.), Psychopathic behavior: Approaches to research (pp. 107-144). New York: John Wiley \& Sons.

Huesmann, L. R. (1982a). Information processing models of behavior. In N. Hirschberg \& L. Humphreys (Eds.), Multivariate applications in the social sciences (pp. 261-288). Hillsdale, NJ: Erlbaum.

Huesmann, L. R. (1982 b). Television violence and aggressive behavior. In D. Pearl, L. Bouthilet, \& J. Lazar (Eds.), Television and behavior: Ten years of scientific programs and implications for the 8o's (Vol. 2, pp. 126-137). Washington, DC: U. S. Government Printing Office.

Huesmann, L. R. (1986). Psychological processes promoting the relation between exposure to 
media violence and aggressive behavior by the viewer. Journal of Social Issues, 42 (3), 125-139.

Huesmann, L. R. (1988). An information processing model for the development of aggression. Aggressive Behavior, 14, 13-24.

Huesmann, L. R. (1995). Screen violence and real violence: Understanding the link (Brochure). Auckland, NZ: Media Aware.

Huesmann, L. R. (1997). Observational learning of violent behavior: Social and biosocial processes. In A. Raine, D. P. Farrington, P. O. Brennen, \& S. A. Mednick (Eds.), The biosocial basis of violence (pp. 69-88). New York: Plenum Press.

Huesmann, L. R. (1998). The role of social information processing and cognitive schema in the acquisition and maintenance of habitual aggressive behavior. In R. G. Geen \& E. Donnerstein (Eds.), Human aggression: Theories, research, and implications for social policy (pp. 73-109). New York: Academic Press.

Huesmann, L. R. (2004). Why those who observe violence behave more violently: Understanding the psychological process. Paper presented at the meetings of the International Society for Research of Aggression, Santorini, Greece.

Huesmann, L. R. (2006). Long-Term Life-Span Effects and Medium-Term Childhood and Adulthood Effects of Media Violence on Aggression: Evidence from 3 Countries. International Communication Association, Dresden, Germany.

Huesmann, L. R., \& Eron, L. D. (Eds.). (1986). Television and the aggressive child: A crossnational comparison. Hillsdale, NJ: Erlbaum.

Huesmann, L. R., \& Miller, L. S. (1994). Longterm effects of repeated exposure to media violence in childhood. In L. R. Huesmann (Ed.), Aggressive behavior: Current perspectives (pp. 153-183). New York: Plenum Press.

Huesmann, L. R., \& Moise-Titus, J. (1999). The role of cognitions in mediating the effects of childhood exposure to violence on adult aggression: $A$ 15-year comparison of youth in four countries. Paper presented at the meeting of the European Society for Developmental Psychology, Spetses, Greece.

Huesmann, L. R., Moise, J. F., \& Podolski, C. L. (1997). The effects of media violence on the development of antisocial behavior. In D. M. Stoff, J. Breiling, \& J. D. Maser (Eds.), Handbook of antisocial behavior (pp. 181-193). New York: John Wiley \& Sons.

Huesmann, L. R., Moise-Titus, J., \& Kirwil, L. (2004, September). The relation between nega- tive emotional reactions to violence and aggression. Paper presented at the XVI World Meeting of the International Society for Research in Aggression, Santorini, Greece.

Huesmann, L. R., Moise-Titus, J., Podolski, C. L., \& Eron, L. (2003). Longitudinal relations between children's exposure to TV violence and their aggressive and violent behavior in young adulthood: 1977-1992. Developmental Psychology, 39, 201-221.

Hurley, S., \& Chater, N. (2005). Perspectives on imitation: From neuroscience to social science. (Vols. 1 \& 2). Cambridge, MA: MIT Press.

Iacoboni, M., Woods, R., Brass, M., Bekkering, H., Mazziotta, J., \& Rizzolatti, G. (1999). Cortical mechanisms of human imitation. Science, 286, 2526-2528.

Ihori, N., Sakamoto, A., Kobayashi, K., \& Kimura, F. (2003). Does video game use grow children's aggressiveness? Results from a panel study. In K. Arai (Ed.), Social contributions and responsibilities of simulation \& gaming (pp. $221-$ 230). Tokyo: Japan Association of Simulation and Gaming.

Johnson, J. G., Cohen, P., Smailes, E. M., Kasen, S., \& Brook J. S. (2002, March 29). Television viewing and aggressive behavior during adolescence and adulthood. Science, $295,2468-2471$.

Josephson, W. L. (1987). Television violence and children's aggression: Testing the priming, social script, and disinhibition predictions. Journal of Personality and Social Psychology, 53 , 882-89o.

Kirwil, L. (2002 a, July). Negative emotional reactions to observed violence as an inhibitor of aggressive behavior: Gender differences. Paper presented at the XV World Meeting of the International Society for Research on Aggression, Montreal, Canada.

Kirwil, L. (2002b). Reakcje emocjonalne kobiet na sceny przemocy ekranowej [Women's Emotional Responses to Screen Violence]. In W. Strykowski \& W. Skrzydlewski (Eds.), Media a edukacja $w$ dobie integracji (pp. 98105). Pozna?: Wydawnictwo eMPiz .

Kirwil, L. (2004a, September). Aggression and emotional arousal in response to violent stimuli: Gender differences. Paper presented at the XVI World Meeting of the International Society for Research in Aggression, Santorini, Greece.

Kirwil, L. (2004b, September). Emotional reactions to violence among police in Poland and Czech Republic. Paper presented at the XVI World Meeting of the International Society for Research in Aggression, Santorini, Greece. 
Kirwil, L., \& Huesmann, L. R. (2003, May). The relation between aggressiveness and emotional reactions to observed violence. Paper presented at the Annual Meeting of Midwestern Psychological Association, Chicago.

Lefkowitz, M. M., Eron, L. D., Walder, L. O., \& Huesmann, L. R. (1977). Growing up to be violent: A longitudinal study of the development of aggression. New York: Pergamon Press.

Leyens, J. P., Camino, L., Parke, R. D., \& Berkowitz, L. (1975). Effects of movie violence on aggression in a field setting as a function of group dominance and cohesion. Journal of Personality and Social Psychology, 32, 346360.

Leyens, J. P., \& Fraczek, A. (1983). Aggression as an interpersonal phenomenon. In H. Tajfel (Ed.), The social dimension (Vol. 1., p. 192). Cambridge: Cambridge University Press.

Linz, D. G., Donnerstein, E., \& Penrod, S. (1988). Effects of long-term exposure to violent and sexually degrading depictions of women. Journal of Personality and Social Psychology, 55, $758-768$.

Lykken, D. T. (1995). The antisocial personalities. Hillsdale, NJ: Erlbaum.

Malamuth, N. M., \& Check, J. V. P. (1981). The effects of mass media exposure on acceptance of violence against women: A field experiment. Journal of Research in Personality, 15, $43^{6}-44^{6}$

McLeod, J. M., Atkin, C. K., \& Chaffee, S. H. $(1972)$. Adolescents, parents and television use: Adolescent self-report measures from Maryland and Wisconsin samples. In G. A. Comstock \& E. A. Rubinstein (Eds.), Television and social behavior: A technical report to the Surgeon General's Scientific Advisory Committee on Television and Social Behavior (Vol. 3) .Washington, DC: U.S. Government Printing Office.

McSweeney, F. K., \& Swindell, S. (2002). Common processes may contribute to extinction and habituation. Journal of General Psychology, $129(4), 364-400$.

Meltzoff, A. N. (2005). Imitation and other minds: The "Like Me" hypothesis. In S. Hurley \& N. Chater (Eds.), Perspectives on imitation: From mirror neurons to memes (Vol. 2, pp. 5578). Cambridge, MA: MIT Press.

Meltzoff, A. N., \& Decety, J. (2003). What imitation tells us about social cognition: A rapprochement between developmental psychology and cognitive neuroscience. Retrieved from www.royalsoc.ac.uk
Meltzoff, A. N., \& Moore, K. M. (1977). Imitation of facial and manual gestures by human neonates. Science, 109, 77-78.

Meltzoff, A. N., \& Moore, K. M. (2000). Resolving the debate about early imitation. In D. Muir (Ed.), Infant development: The essential readings (pp. 167-181). Malden, MA: Blackwell Publishers.

Milavsky, J. R., Kessler, R., Stipp, H., \& Rubens, W. S. (1982). Television and aggression: Results of a panel study. In D. Pearl, L. Bouthilet, \& J. Lazar (Eds.), Television and behavior: Ten years of scientific progress and implications for the eighties. Vol. 2: Technical reviews (DHHS Publication No. ADM 82-1196, pp. 138-157). Washington, DC: U.S. Government Printing Office.

Moise-Titus, J. (1999). The role of negative emotions in the media violence-aggression relation. Unpublished doctoral dissertation, University of Michigan, Ann Arbor.

Molitor, F., \& Hirsch, K. W. (1994). Children's toleration of real aggression after exposure to media violence: A replication of the Drabman and Thomas studies. Child Study Journal, 24 , 191-207.

Nathanson, A. (1999). Identifying and explaining the relationship between parental mediation and children's aggression. Communication Research, 26(2), 124-143.

Neuman, R., \& Strack, F. (2000). "Mood contagion": The automatic transfer of mood between persons. Journal of Personality and Social Psychology, 79, 211-223.

Oliver, M. B. (2004). Desensitization from longterm exposure to graphic violence. Unpublished manuscript, Pennsylvania State University.

Paik, H., \& Comstock, G. (1994). The effects of television violence on antisocial behavior: A meta-analysis. Communication Research, 21 , 516-546.

Press, C., Bird, G., Flach, R., \& Heyes, C. (2005). Robotic movements elicit automatic imitation. Cognitive Brain Research, 25, 632-640.

Pantalon, M. V., \& Motta, R. W. (1998). Effectiveness of anxiety management training in the treatment of posttraumatic stress disorder: A preliminary report. Journal of Behavior Therapy and Experimental Psychiatry, 29, 21-29.

Phillips, D. P. (1979). Suicide, motor vehicle fatalities, and the mass media: Evidence toward a theory of suggestion. American Journal of Sociology, 84, 1150-1174.

Prinz, J. J. (2005). Imitation and moral development. In S. Hurley \& N. Chater (Eds.), 
Perspectives on imitation: From mirror neurons to memes (Vol. 2, pp. 267-282). Cambridge, MA: MIT Press.

Raine, A. (1993). The psychopathology of crime. San Diego: Academic Press.

Raine, A., Dodge, K., Loeber, R., Gatzke-Kopp, L., Lynam, D., Reynolds, C., et al, (2006). Proactive and reactive aggression in adolescent boys. Aggressive Behavior, 32 (2), 159-171.

Raine, A., Reynolds, C., Venables, P. H., \& Mednick, S. A. (1997). Biosocial bases of aggressive behavior in childhood. In A. Raine, D. P. Farrington, P. O. Brennen, \& S. A. Mednick (Eds.), The biosocial basis of violence (pp. 107126). New York: Plenum Press.

Raine, A., Venables, P. H., \& Williams, M. (1990). Relationships between CNS and ANS measures of arousal at age 15 and criminality at age 24. Archives of General Psychiatry, 47, 10031007 .

Rhodes, R. (2000, September 17). Hollow claims about fantasy violence. New York Times, pp. $4^{-19}$.

Rizzolatti, G. (2005). The mirror neuron system and imitation. In S. Hurley \& N. Chatter (Eds.), Perspectives on imitation: From mirror neurons to memes. (Vol. 1, pp. 55-76). Cambridge, MA: MIT Press.

Savage, J. (2004). Does viewing violent media really cause criminal violence? A methodological review. Aggression and Violent Behavior, 10, 99-128.

Schaal, S. (1999). Is imitation learning the route to humanoid robots? Trends in Cognitive Science, $3,233-242$.

Schneider, W., \& Shiffrin, R. M. (1977). Controlled and automatic human information processing: I. Detection, search, and attention. Psychological Review, 84, 1-66.

Shiffrin, R. M., \& Schneider, W. (1977). Controlled and automatic human information processing: II. Perceptual learning, automatic attending, and general theory. Psychological Review, 84, 127-19o.

Slater, M. D., Henry, K. L., Swaim, R. C., \& Anderson, L. L. (2003). Violent media content and aggressiveness in adolescents: A downward spiral model. Communication Research, 30, 713-736.
Strelau, J. (1982). Biologically determined dimensions of personality or temperament? Personality and Individual Differences, 3, 355360.

Surette, R. (2002). Self-reported copycat crime among a population of serious and violent juvenile offenders. Crime and Delinquency, $4^{8}$, 46-69.

Thomas, M. H., \& Drabman, R. S. (1975). Toleration of real life aggression as a function of exposure to televised violence and age of subject. Merrill-Palmer Quarterly, 21, 227232.

Thomas, M. H., Horton, R. W., Lippincott, E. C., \& Drabman, R. S. (1977). Desensitization to portrayals of real-life aggression as a function of television violence. Journal of Personality and Social Psychology, 35, 450458.

Uhlmann, E., \& Swanson, J. (2004). Exposure to violent video games increases automatic aggressiveness. Journal of Adolescence, 27, 4152.

van der Voort, T. H. A. (1986). Television violence: A child's-eye view. New York: Elsevier Science.

Viemero, V. (2002). Factors predicting aggression in early adulthood. Psykologia, 37 (2), 138-144.

Wolpe, J. (1958). Psychotherapy by reciprocal inhibition. Stanford, CA: Stanford University Press.

Zajonc, R. B., Murphy, S. T., \& Inglehart, M. (1989). Feeling and facial efference: Implications of vascular theory of emotions. Psychological Review, 96, 395-416.

Zillmann, D. (1982). Television viewing and arousal. In D. Pearl, L. Bouthilet, \& J. Lazar (Eds.), Television and behavior: Ten years of scientific progress and implications for the eighties. Vol. 2: Technical reviews (DHHS Publication No. ADM 82-1196, pp. 53-67). Washington, DC: U.S. Government Printing Office.

Zillmann, D., Bryant, J., Cominsky, P. W., \& Medoff, N. J. (1981). Excitation and hedonic valence in the effect of erotica on motivated intermale aggression. European Journal of Social Psychology, 11, 233-252

Zuckermann, M. (1979). Sensation seeking: Beyond the optimal level of arousal. Hillsdale, NJ: Erlbaum. 